\title{
On Quitting Rights in Mechanism Design
}

\author{
Olivier Compte and Philippe Jehiel*
}

Quitting rights play a major role in many economic interactions whether in the precontractual phase or even after contracts have been signed. Clearly, no party can be forced to sign a contract if she is unwilling to, thus implying that quitting rights can always be exerted at the ex-ante stage where no contract has been signed yet. But, quitting rights can also be exerted even after explicit contracts have been signed in a number of instances. For example, most labor contracts allow employees to leave their job if they want to. Also, quitting rights may be asymmetric across agents as labor contracts illustrate: employers are generally constrained in their ability to replace their employees.

Mechanism design - the methodological apparatus used by contract theory - models quitting rights in terms of participation constraints, formalizing the idea that every agent should voluntarily agree to participate in the mechanism. Several forms of participation constraints are typically considered: The interim participation constraint stipulates that

*Jehiel (corresponding author): PSE and UCL, 48 Bd Jourdan 75014 Paris, France; e-mail: jehiel@enpc.fr. Compte: PSE; e-mail: compte@enpc.fr. 
an agent should voluntarily agree to participate in the mechanism at the interim stage, that is, based on his sole private information (and not based on further information like the private information held by other agents or the realization of some random event). The ex-post participation constraint stipulates that even after the equilibrium outcome of the mechanism has been revealed, the agent should still find staying in the mechanism worthwhile, as compared to his interim alternative.

The ex-ante quitting rights described above are equivalent to the interim participation constraints considered in the mechanism design literature. Ex-post quitting rights imply ex-post participation constraints, but they also affect the derivation of the incentive constraints, as an agent enjoying ex-post quitting rights retains the right to quit ex-post whatever his choice of strategy and not only for the strategy that he effectively chooses in equilibrium. This simple observation will be illustrated in a stylized labor contract environment in Section I.

In Section II we revisit some classic insights obtained in the mechanism design literature with correlated private information, assuming that all or some agents enjoy ex-post quitting rights. In a simple yet standard bargaining setup in which each party's private information bears on his outside option, inefficiencies are inevitable when all parties can exert their quitting rights at the ex-post stage and the private information -no matter how correlated it is- is dispersed (see Compte and Jehiel, 2006). When only one party can leave ex-post (call this party the employee), efficiency can in principle be achieved whenever private signals are correlated. But, efficiency comes at the cost 
of leaving a significant informational rent to the agent enjoying ex-post quitting rights. As we show, an efficient outcome - even though feasible - will not obtain if private information is dispersed and the contract is chosen by the party who has no quitting right ex-post (call this party the employer): distorting the outcome away from efficiency allows the employer to reduce the informational rent left to the employee by an amount that offsets the lost surplus, thereby illustrating the conflict between private and social interest in such situations whatever the exact form of correlation.

\section{Quitting Rights and Incentive Constraints}

We consider an employer/employee relationship with two types of employees: the skilled employees and the unskilled employees, all assumed to be risk neutral; skills are firm specific. We take as given the contractual relationship, and examine how quitting rights affect the incentive of the unskilled employee to imitate the skilled employee.

The contract requires the employee to choose between two tasks, a routine task (task b), and a potentially more rewarding but riskier task (task $a$ ). Soon after choosing a task (and before the term of the contract), the employee learns the realization of the output. By contract, the output will accrue to the employee, provided that he remains in the firm until the term of the contract. An employee who has quitting rights and exercizes them before the term of the contract gets $w$, where $w$ can be thought of as a reservation wage available in the market for all employees.

We assume the following productive technology. The routine task $b$ delivers output 
$\underline{Y}>0$ for sure whatever the type of the employee. The potentially riskier task $a$ delivers either output $\bar{Y}(>\underline{Y})$ or output 0 . It delivers output $\bar{Y}$ with probability 1 if the employee is skilled, and with probability $p<1$ if the employee is unskilled. We assume that $p \bar{Y}<\underline{Y}<\bar{Y}$ so that in expectation the routine task $b$ is more productive than the riskier task $a$ for an unskilled employee, and task $a$ is more productive than task $b$ for the skilled employee. We also assume that the reservation wage $w$ is set in between 0 and $\underline{Y}$ (thereby capturing situations in which the routine task in the firm is more productive than the average task that the employee can perform outside the firm).

Clearly, in this environment the skilled employee chooses task $a$ as this delivers a greater output. If the unskilled employee were to choose task $b$ he would get a payoff equal to $\underline{Y}$, and he would not leave his job as $\underline{Y}>w$. The incentive constraints as usually considered in the mechanism design literature would suggest that the unskilled employee does not imitate the skilled employee since in expectation task $b$ is more productive than task $a$ for the unskilled employee $(p \bar{Y}<\underline{Y})$. So if the employee is not entitled to leave his job before the term of the contract, the unskilled employee performs task $b$ and his ex-post participation constraint would be satisfied as this employee would have no regret for not having left the firm at the ex-ante stage.

The incentive analysis is different when the employee can quit his job before the term of the contract. In such a case, the unskilled employee values task $a$ according to $p \bar{Y}+(1-p) w$ (and not $p \bar{Y})$ as he can always quit the firm and get $w$ whenever the outcome of the risky task is not good. Thus, if $p \bar{Y}+(1-p) w>\underline{Y}$, the unskilled 
employee prefers to imitate the skilled employee, and perform task $a$ rather than task $b$, thereby illustrating how quitting rights affect incentive constraints.

The point is, of course, very simple. Quitting rights affect the incentive constraints because they can be exerted even after a potential deviation of the agent (here task $a$ rather than $b$ ), thereby affecting the way the agent values the various alternatives. Quitting rights do not reduce to ex-post participation constraints because requiring that ex-post participation constraints be satisfied for all types does not ensure that incentive constraints can be written as if agents had no further quitting rights after any potential deviation. A related observation appears in Matthews and Postlewaite (1989), Forges (1999), and Compte and Jehiel (2006).

\section{Bargaining with Quitting Rights}

Consider a bargaining problem between two parties $i=1,2$ who bargain on the division of a pie of known size 1. Each party $i$ is privately informed of his outside option denoted $w_{i} \in[0,1]$, and we allow for any form of correlation in the distribution of outside options. We also allow third parties to help reaching better bargaining outcomes.

\section{A. When all parties can quit}

This subsection summarizes the main result in Compte and Jehiel (2006). Assume that all parties can quit the bargaining table at any point in time, thereby capturing situations with limited commitment abilities. Any equilibrium outcome of any bargaining 
game can be viewed as the outcome of a direct truthful mechanism (this is an expression of the well known revelation principle). Direct mechanisms can be represented as $\left(\phi, t_{1}, t_{2}\right)$ where $\phi:[0,1]^{2} \rightarrow[0,1], t_{i}:[0,1]^{2} \rightarrow \mathbb{R}$ and $\phi(\widehat{w})$ is the probability of agreement conditional on the profile of announcement $\widehat{w}=\left(\widehat{w}_{1}, \widehat{w}_{2}\right)$ and $t_{i}(\widehat{w})$ is the monetary transfer received by $i$ when there is agreement and the profile of announcements is $\widehat{w}$ (providing non-zero transfers in the disagreement case would violate the quitting right of either party 1, 2 or the third party, thereby justifying that they are not considered here).

Quitting rights impose that after any conceivable announcement $\widehat{w}$ party $i$ with outside option $w_{i}$ should get no less than $w_{i}$. The quitting right of the third party also implies that the two parties should never receive any subsidy ex-post, i.e. $t_{1}(\widehat{w})+t_{2}(\widehat{w}) \leq$ 1 for all $\widehat{w}$.

A direct mechanism is truthful if it is a Bayes-Nash equilibrium to announce the true private outside option for each party. We may without loss of generality assume that $t_{i}\left(w_{1}, w_{2}\right) \geq w_{i}$ whenever there is agreement as otherwise party $i$ would quit when $w=\left(w_{1}, w_{2}\right)$ and there would be no agreement. This is the usual ex-post participation constraint.

In order to express the incentive constraints with ex-post quitting rights, we let $U_{i}\left(\widehat{w}_{i} ; w_{i}\right)$ denote the expected payoff obtained by party $i$ when party $i$ 's outside option is $w_{i}$, party $i$ 's announcement is $\widehat{w}_{i}$ and party $i$ expects party $j, j \neq i$ to report truthfully. The incentive constraints with ex-post quitting rights then write $U_{i}\left(w_{i} ; w_{i}\right) \geq U_{i}\left(\widehat{w}_{i} ; w_{i}\right)$ 
for all $\widehat{w}_{i}, w_{i}$ where

$$
U_{i}\left(\widehat{w}_{i} ; w_{i}\right)=E_{w_{j}}\left\{\max \left[t_{i}\left(\widehat{w}_{i}, w_{j}\right), w_{i}\right] \phi\left(\widehat{w}_{i}, w_{j}\right)+w_{i}\left(1-\phi\left(\widehat{w}_{i}, w_{j}\right)\right) \mid w_{i}\right\}
$$

since party $i$ with type $w_{i}$ can always secure $\max \left[t_{i}\left(\widehat{w}_{i} ; w_{j}\right), w_{i}\right]$ whenever she claims she has type $\widehat{w}_{i}$ and party $j$ 's type is $w_{j}$. The main result is:

Theorem 1: For any smooth density of $\left(w_{1}, w_{2}\right)$ on $[0,1]^{2}$, inefficiencies are inevitable when all parties have ex-post quitting rights.

This result complements an important insight by Roger Myerson and Mark Satterthwaite (1983) showing a related inefficiency result for the case in which the private information is independently distributed between parties. The main differences are that 1) correlation is allowed (thereby making the technique of proof very different) and 2) ex-post quitting rights (as opposed to interim participation constraints) are considered here. The result contrasts with the insight obtained by Jacques Crémer and Richard Mclean (1988) showing that efficiency should be expected whenever there are correlations and only interim participation constraints are required. The main difference with Crémer and McLean is that parties have ex-post quitting rights here, whereas the usual interim participation constraints are considered in Crémer and McLean.

To prove the theorem, we show that the incentive constraints of party $i$ together with the constraints that $w_{i} \leq t_{i}\left(w_{i}, w_{j}\right) \leq 1-w_{j}$ (which follow from the ex-post no subsidy constraint and the ex-post participation constraints of the two parties) force party $i$ to get the entire surplus whenever one insists on having an efficient outcome for 
all realizations. Thus, one should have $\phi\left(w_{i}, w_{j}\right)=1$ and $t_{i}\left(w_{i}, w_{j}\right)=1-w_{j}$ whenever $w_{i}+w_{j} \leq 1$. But, this cannot hold simultaneously for parties 1 and 2 as this would require external subsidies $\left(t_{1}(w)+t_{2}(w)>1\right.$ whenever $\left.w_{i}+w_{j}<1\right)$. To establish that $t_{i}\left(w_{i}, w_{j}\right)=1-w_{j}$ for all $\left(w_{i}, w_{j}\right)$, we use an induction argument starting from large values of $w_{i}$. Clearly, this is true for $w_{i}=1$ as party $i$ can always quit. Assuming it is true for any $w_{i} \geq z$, we show it is true for $w_{i}=z-\varepsilon$ by considering a deviation of type $w_{i}=z-\varepsilon$ to $\widehat{w}_{i}=z$ (which gives a lower bound on what type $w_{i}$ should get): for any $w_{j}<1-z$, the induction argument ensures that party $i$ gets the maximal surplus, and for $w_{j} \in(1-z, 1-z+\varepsilon)$ party $i$ can always quit thereby getting (almost) the entire surplus. Thus, (up to $\varepsilon^{2}$ terms) party $i$ with type $w_{i}=z-\varepsilon$ must get the entire surplus in expectation and the only way to achieve this is to let $t_{i}\left(w_{i}, w_{j}\right)=1-w_{j}$ for all $w_{j}<1-w_{i}$, given that $t_{i}\left(w_{i}, w_{j}\right) \leq 1-w_{j}$.

\section{B. When only one party can quit}

We now assume that only party 2 can exert her quitting rights ex-post while both party 1 and the third party have no such right (they still have the interim quitting right). For simplicity, we assume that outside options can take their values on the finite grid $k \varepsilon, k=0, \ldots K$ where $K \varepsilon=1^{-}$. We let $g\left(w_{1}, w_{2}\right)$ be the probability that parties 1 and 2's outside options are $w_{1}$ and $w_{2}$, respectively, and we assume that the correlation matrix $\left[g\left(k_{1} \varepsilon, k_{2} \varepsilon\right)\right]_{k_{1}, k_{2}}$ has full rank. We now allow party 1 to receive a transfer $t_{1}^{o}(\widehat{w})$ when there is no agreement and the announcement is $\widehat{w}$ while party 2 is still assumed to receive no transfer in such a case (this is enough to establish Proposition 2). We 
still let $t_{i}(\widehat{w})$ denote the transfer received by party $i$ in case of agreement. The change in the quitting right of the third party implies that the budget constraint should now only be balanced at the ex-ante stage and not necessarily at the ex-post stage. That is, budget-balancedness writes:

$$
E_{w}\left\{\left(t_{1}(w)+t_{2}(w)-1\right) \phi(w)+t_{1}^{o}(w)(1-\phi(w))\right\} \leq 0 .
$$

The change in party 1's quitting right implies that the expected utility of party 1 with type $w_{1}$ when announcing type $\widehat{w}_{1}$ should now write

$$
U_{1}\left(\widehat{w}_{1} ; w_{1}\right)=E_{w_{2}}\left\{t_{1}\left(\widehat{w}_{1}, w_{2}\right) \phi\left(\widehat{w}_{1}, w_{2}\right)+\left(w_{1}+t_{1}^{o}\left(\widehat{w}_{1}, w_{2}\right)\right)\left(1-\phi\left(\widehat{w}_{1}, w_{2}\right)\right) \mid w_{1}\right\}
$$

Party 1's incentive constraints write $U_{1}\left(w_{1} ; w_{1}\right) \geq U_{1}\left(\widehat{w}_{1} ; w_{1}\right)$ while party 1 's interim participation constraints write $U_{1}\left(w_{1} ; w_{1}\right) \geq w_{1}$. Party 2 's incentive constraints write as in subsection A while party 2's quitting rights also imply that $t_{2}\left(w_{1}, w_{2}\right) \geq w_{2}$. We have:

Proposition 2: Under the full rank assumption, the first-best outcome can be achieved when only party 2 has ex-post quitting rights.

Proof (sketch): Consider an efficient mechanism satisfying $\phi\left(w_{1}, w_{2}\right)=1$ whenever $w_{1}+w_{2} \leq 1$ with $t_{2}\left(w_{1}, w_{2}\right)=1-w_{1}$ and $\phi\left(w_{1}, w_{2}\right)=0$ otherwise. That is, the entire surplus is left to agent 2 who is then willing to reval his type. Due to the full rank assumption, the Crémer-McLean mechanism allows us to implement $\phi$ while choosing $t_{1}\left(w_{1}, w_{2}\right)$ and $t_{1}^{o}\left(w_{1}, w_{2}\right)$ so that agent 1 is set to his participation constraint for every 
$w_{1}$, i.e. $U_{1}\left(w_{1} ; w_{1}\right)=w_{1}$ for all $w_{1}$ (roughly, this amounts to choosing VCG transfers augmented by appropriate outcome independent transfers that depend only on $w_{2}$ ). The ex-ante budget-balancedness is then satisfied because for every $w_{1}$, the expected value of $\left(t_{1}(w)+t_{2}(w)-1\right) \phi(w)+\left(t_{1}^{o}(w)+t_{2}^{o}(w)\right)(1-\phi(w))$ is 0 , conditional on $w_{1}$. Q.E.D.

Proposition 2 tells us that efficiency can be achieved, but will an efficient mechanism be chosen if party 1 is in charge of choosing it? This is in fact less than clear. The mechanism constructed to prove Proposition 2 gives the entire surplus to party 2. Party 1 would clearly not use such a mechanism, as there are obvious ways for party 1 to derive positive surplus, for example, by making a take-it-or-leave-it offer to party 2 . It turns out that for the following class of distributions, efficency requires that party 2 gets the entire surplus. In this class, an efficient mechanism will thus not be chosen by party 1 .

Proposition 3: Assume that $g\left(w_{1}, w_{2}\right) \cdot g\left(w_{1}^{\prime}, w_{2}^{\prime}\right)=g\left(w_{1}^{\prime}, w_{2}\right) \cdot g\left(w_{1}, w_{2}^{\prime}\right)$ for all $w_{1}, w_{1}^{\prime}, w_{2}, w_{2}^{\prime}$ s. t. $\max \left(w_{1}, w_{1}^{\prime}\right)+\max \left(w_{2}, w_{2}^{\prime}\right) \leq 1$. Consider an efficient mechanism in which party 2 enjoys ex-post quitting rights. Party 2 with outside option $w_{2}$ must receive the entire surplus, i.e. $E_{w_{1}}\left[\max \left(1-w_{1}, w_{2}\right) \mid w_{2}\right]$.

Proof (sketch): This is shown by induction on $k$ considering the deviation from $w_{2}^{k}=1-k \varepsilon$ to $\widehat{w}_{2}^{k}=w_{2}^{k-1}$, and observing that the assumption on the distributions and the induction hypothesis implies that party 2 must get the entire surplus in expectation over those realizations of $w_{1}$ such that $w_{1} \leq 1-\widehat{w}_{2}^{k}$. Q. E. D.

More generally, we conjecture that: 
Theorem 4: Whatever the probabilities $g\left(k_{1} \varepsilon, k_{2} \varepsilon\right)$ assumed to be all strictly positive, the best mechanism for party 1 requires some distortion away from efficiency whenever party 2 has ex-post quitting rights.

While a complete proof is not yet available, our intuition for it comes from the following observation. In an efficient mechanism, party 2 with outside option $w_{2}=1-\varepsilon$ should receive the entire surplus given that he can mimick type $\widehat{w}_{2}=1^{-}$and quit whenever $w_{1}=\varepsilon$. Thus, party 1 receives no surplus at all when $w_{2}=1-\varepsilon$. Rather than offering an efficient mechanism, party 1 should be better off letting parties go for their outside options whenever $w_{2} \geq 1-\varepsilon$, thereby permitting a relaxation of the incentive constraints of lower types $w_{2}$. The argument would be a proof if we were sure that the incentive constraint to mimick type $1-\varepsilon$ were binding for some $w_{2}<1-\varepsilon$. While this sounds intuitively correct, more work is required to establish it formally.

The above analysis suggests the following discussion. The ex-post quitting right of party 2 can be viewed as providing a form of protection to party 2 (against the privilege of party 1 to choose the contract). Yet, this mere protection leads party 1 to choose an inefficient mechanism. Analyzing the pros and the cons of such a protection from an efficiency and distributive viewpoint is left for future research. 


\section{References}

[1] Olivier Compte and Philippe Jehiel (2006): "Veto Constraints in Mechanism Design: Inefficiency with Correlated Types," mimeo PSE and UCL.

[2] Jacques Crémer and Richard McLean (1988): "Full Extraction of the Surplus in Bayesian and Dominant Strategy Auctions," Econometrica, 56 1247-1257.

[3] Françoise Forges (1999): "Ex post Individually Rational Trading Mechanisms", in Current trends in Economics, Springer-Verlag, 157-175, Alkan,A. C. Aliprantis and N. Yannelis (eds).

[4] Steven Matthews and Andrew Postlewaite (1989), "Pre-play Communication in Two-Person Sealed-Bid Double Auctions", Journal of Economic Theory, 48, 238263.

[5] Roger Myerson and Mark Satterthwaite (1983): "Efficient Mechanisms for Bilateral Trading," with M. Satterthwaite, Journal of Economic Theory, 29, 265-281. 